\title{
ANALISIS TERAPI PADA PASIEN TUKAK PEPTIKDI SMF PENYAKIT DALAM RSUD DR. ACHMAD MOCHTAR BUKITTINGGI
}

\author{
Suhatri, Hansen, Hengky \\ Fakultas Farmasi, Unversitas andalas, Padang
}

\begin{tabular}{l}
\hline KATA KUNCI \\
\hline \multicolumn{2}{l}{ Tukak peptik, } \\
pemeriksaan fisik, terapi
\end{tabular}

\section{PENDAHULUAN}

Tukak peptik merupakan gangguan saluran pencernaan yang sering terjadi.Di USA kirakira 4 juta orang menderita tukak peptic, 150.000 kasus baru didiagnosis tiap tahunnya dan sekitar 180.000 pasien tukak harus di rawat di rumah sakit serta kurang lebih 5.000 pasien tukak peptik meninggal tiap tahunnya ${ }^{1}$. Insiden tertinggi tukak peptik biasa terjadi akibat infeksi Helicobacter pylori, dan biasanya yang sering terkena infeksi adalah masyarakat dengan. Angka mortalitas meningkat pada orang tua, berhubungan dengan penggunaan obat anti inflamasinon steroid (OAINS). Di Indonesia sekitar 4 juta orang menderita tukak peptik dengan prevalensi $1.84 \%$, dan prevalensi Helicobacter pylori pada rumah sakit di Surabaya adalah $93,9 \%{ }^{2}$.

Secara garis besar ada tiga faktor penyebab dari tukak peptik diantaranya Helicobacter pylori, penggunaan OAINS dan kerusakan mukosa yang berhubungan dengan stres $^{3}$. Sejak ditemukan bakteri Helicobacter pylori oleh Barry Marshall dan Robin Warren pada tahun 1982, terbukti bahwa Helicobacter pylori penyebab utama penyakit tukak peptik yang sebelumnya stres dan gaya hidup masih 
dianggap sebagai penyebab utama tukak. Helicobacter pylori ditemukan lebih dari $90 \%$ pasien yang mengalami tukak duodenum dan $70 \%$ pasien yang mengalami tukak lambung ${ }^{4,5}$. Menurut Kimble (2005) Helicbacter pylori merupakan bakteri gram negatif yang berbentuk spiral membentuk koloni pada bagian bawah lambung (pada bagian pylorus atau pada daerah perbatasan dengan usus).

Tujuan dari terapi tukak peptik adalah mematikan bakteri Helicobacter pylori dan mengontrol kadar asam lambung yang berlebihan yang dapat memperburuk kondisi tukak. Terapi tunggal antibiotik atau terapi tunggal obat penurun kadar asam terbukti tidak optimal untuk mengobati tukak yang disebabkan oleh karena infeksi bakteri Helicobacter pylori. Oleh sebab itu untuk pasien yang positif Helicobacter pylori diperlukan suatu kombinasi terapi yang terdiri dari antibiotika yang mampu menurunkan kadar asam lambung (misalnya penghambat pompa proton atau antagonis reseptor $\left.\mathrm{H}_{2}\right)^{5,6}$.

Tukak peptik dapat memicu terjadinya luka dan menyebabkan pendarahan pada lambung dan usus ${ }^{7}$. Hal ini terjadi karena terlambatnya mengetahui faktor-faktor penyebab tukak peptik. Tukak peptik penyebabnya dapat diketahui dari hasil pemeriksaan fisik secara dini, dapat ditentukan pilihan terapi selanjutnya agar tercapai hasil yang optimal. Keterampilan dan pengetahuan farmasi sebagai tenaga kesehatan tentang hasil pemeriksaan fisik sangat penting dilakukan dalam mengevaluasi terapi obat dan penyakit ${ }^{8}$. Berdasarkan uraian yang telah dipaparkan maka dilakukan penelitian tentang hubungan hasil pemeriksaan fisik dengan pilihan terapi pada pasien tukak peptik di SMF penyakit dalam RSUD Dr. Achmad Mochtar Bukittinggi. Penelitian ini bertujuan untuk mengetahui apakah ada hubungan hasil pemeriksaan fisik menjadi dasar dalam pemberian terapi pada pasien tukak peptik. Selain itu diharapkan supaya farmasi sebagai tenaga kesehatan memahami sebelum pemberian pengobatan kepada pasien sehingga tercapai terapi yang optimal.

\section{METODE PENELITIAN}

\section{Waktu dan Tempat Penelitian}

Waktu penelitian daribulan Februari sampai April 2012 di SMF Penyakit Dalam RSUD Dr. Achmad Mochtar Bukittinggi.

\section{Metode Penelitian}

Penelitian ini adalah penelitian prospektif, pengambilan sampel dilakukan dengan metode purposive sampling .

\section{Prosedur Penelitian}

Penetapan kriteria pasien yang akan dievaluasi

Seluruh pasien tukak peptik di SMF Penyakit Dalam RSUD Dr. Achmad Mochtar Bukittinggi. 


\section{Pengambilan data}

Data diperoleh dari rekam medik pasien berupa keluhan dan terapi yang diterima. Selain itu data juga diperoleh dengan cara menggali informasi dari pasien dengan meminta pasien untuk menunjukkan lokasi nyeri pada bagian perutnya. Untuk lokasi nyeri yang disebabkan oleh Helicobacter pylori adalah pada daerah antrum atau perut bawah bagian kiri, tukak disebabkan penggunaan OAINS dan stres lokasi nyeri pada daerah korpus/fundus atau ulu hati untuk mengetahui kondisi penyakit pasien, untuk tukak akibat Helicobacter pylori dan OAINS kondisinya kronis dengan keluhan atau nyeri yang dirasakan sudah lama dan terus menerus dan tukak akibat stres kondisinya akut dengan keluhan nyeri yang dirasakan timbul secara mendadak dan berbahaya 9 .

\section{Analisis data dan penarikan kesimpulan}

Data kualitatif dikumpulkan dan diolah dengan secara deskriptif. Data disajikan dalam bentuk tabel kemudian dianalisa untuk mengetahui apakah hasil pemeriksaan fisik telah menjadi rujukan dalam pemberian terapi selanjutnya.

\section{HASIL PENELITIAN}

\section{Jenis kelamin pasien}

Pada penelitian ini menunjukkan bahwa pasien tukak peptik tertinggi terjadi pada pasien berjenis kelamin laki-laki yaitu sebanyak 28 pasien $(56 \%)$. Data selengkapnya dapat dilihat pada tabel (1).

Tabel 1 Distribusi frekuensi jenis kelamin pasien tukak peptic

\begin{tabular}{cccc}
\hline \multirow{2}{*}{ No } & \multirow{2}{*}{ Jenis kelamin } & Jumlah pasien & $\%$ \\
\hline 1 & Laki-laki & 28 & 56 \\
2 & Perempuan & 22 & 44 \\
\hline & Total & 50 & 100 \\
\hline
\end{tabular}

Hasil penelitian ini sesuai dengan penelitian sebelumnya dengan medication use evaluation study di RS. Lebanese Lebabnon yang dilakukan pada bulan Juli 2009 Februari 2010 dan menyatakan pasien lakilaki menderita tukak peptik tertinggi yaitu sebesar $52,5 \%{ }^{10}$.

\section{Keluhan klinis pasien}

Keluhan klinis yang sering dialami pada pasien adalah nyeri perut, mual, muntah, nyeri perut pada malam hari.Hal ini sesuai dengan studi yang menyatakan bahwa keluhan pada penderita tukak peptik adalah nyeri perut, mual, muntah, nyeri perut pada malam hari ${ }^{9,11}$.

\section{Hasil pemeriksaan fisik}

Tabel 2. Distribusi frekuensi keluhan klinis pasien

\begin{tabular}{llll}
\multicolumn{2}{c}{ tukak peptik } & & \\
\hline No & Keluhan klinis & $\begin{array}{l}\text { Jml } \\
\text { pasien }\end{array}$ & $\%$ \\
\hline 1 & Nyeri perut & 50 & 100 \\
2 & Mual & 42 & 84 \\
3 & Muntah & 33 & 66 \\
\hline 4 & Nyeri perut pada malam & 23 & 46 \\
& hari & & \\
\hline
\end{tabular}


Obat antitukak yang digunakan dalam terapi

Terapi tukak peptik yang diberikan dalam penelitian ini adalah $\mathrm{H}_{2} \mathrm{RA}$ (ranitidin), PPI (Omeprazol dan lansoprazol), antasida, sukrafalt, dan tidak ditemukan terapi yang menggunakan antibiotik. Menurut hasil penelitian dari hasil pemeriksaan fisik, sebanyak 19 pasien (38\%) dicurigai faktor penyebab tukaknya adalah Helicobacter pylori (berdasarkan pemeriksaan fisik untuk penyakit tukak peptik dapat dilakukan dengan menggali informasi dengan mengajukan pertanyaan, seperti di mana lokasi nyeri pada perut dan kondisi penyakit.Untuk lokasi nyeri yang disebabkan oleh Helicobacter pylori adalah pada daerah antrum atau perut bawah bagian kiri terlihat pada tabel 5). Di RSUD Dr. Achmad Mochtar sendiri tidak dilakukan pemeriksaan Helicobacter pylori, oleh karena itu, apoteker dalam menjalankan asuhan kefarmasiannya merekomendasikan untuk diadakan tes Helicobacter pylori sehingga bisa dipastikan penggunaan terapi antibiotika guna tercapainya keberhasilan terapi yang optimal. Helicobacter pylori penyebab utama penyakit tukak peptik, 95\% menyebabkan tukak duodenum dan 70\% menyebabkan tukak gaster. Pemberian terapi antitukak dan antibiotika untuk eradikasi Helicobacter pylori selama 1-2 minggu dapat mempercepat penanganan tukak peptik dan tukak duodenum $^{12}$.
Penyakit tukak peptik akibat penggunaan OAINS dalam penelitian ini sebanyak 5 pasien (10\%) dan gabungan $H$ pylori dengan OAINS sebanyak 8 pasien (16\%).Hal ini terjadi karena pasien menderita penyakit radang sendi dan kemungkinan menggunakan OAINS tanpa resep dokter. Hasil tersebut sesuai dengan penelitian di Nigeria yang menyatakan bahwa lebih dari 93\% responden menggunakan OAINS tanpa resep dokter dan $52,9 \%$ responden percaya dengan menggunakan kombinasi dua atau lebih OAINS akan menghilangkan rasa sakit lebih cepat (Awofisayo, et al., 2008).OAINS ini memiliki banyak efek samping, antara lain gangguan saluran cerna. Efek samping obat ini bisa terjadi kapanpun saat penggunaan obat, tapi resiko efek samping akan meningkat jika durasi penggunaan dalam jangka panjang dan dosis yang besar $^{14,15,16}$.

Tabel 3 Distribusi penggunaan obat antitukak pada \begin{tabular}{clc}
\multicolumn{3}{c}{ pasien tukak peptik } \\
\hline $\mathrm{N}$ & Golongan obat antitukak & $\begin{array}{c}\text { Persentase } \\
(\%)\end{array}$ \\
\hline 1 & $\mathrm{H}_{2} \mathrm{RA}$ & 22 \\
2 & $\mathrm{H}_{2} \mathrm{RA}+$ Antasida & 14 \\
3 & $\mathrm{H}_{2}$ RA+ Sukrafalt & 12 \\
4 & $\mathrm{H}_{2} \mathrm{RA}+$ PPI & 16 \\
5 & Sukrafalt & 4 \\
6 & PPI & 4 \\
7 & PPI+ Sukrafalt & 12 \\
8 & $\mathrm{H}_{2} \mathrm{RA}+\mathrm{PPI}+$ Sukrafalt & 14 \\
9 & $\mathrm{H}_{2} \mathrm{RA}+$ PPI+ Antasida & 2 \\
\hline \multicolumn{2}{c}{ Total } \\
\hline
\end{tabular}

\section{Faktor penyebab tukak peptic}

Dari data hasil pemeriksaan fisik didapat berupa faktor penyebab tukak peptik. Faktor penyebab penyakit tukak peptik lebih dominan dicurigai oleh Helicobacter pylori 
sebanyak 19 pasien (38\%) dan stres sebanyak 18 pasien (36\%), sisanya disebabkan oleh penggunaan OAINS sebanyak 5 pasien (10\%) dan Helicobater pylori dan OAINS sebanyak 8 pasien (16\%). Data selengkapnya dapat dilihat pada tabel (4).

Penggunaan OAINS pada penyakit radang sendi, lokasi nyeri dirasakan pada lambung yaitu di daerah antrum dan fundus. Dalam penelitian ini, sebagian besar penyakit sudah kronis dicurigai penyebabnya Helicobacter pylori, karena ada keluhan nyeri lambung pada daerah antrum sebanyak 27 pasien.Terdapat 13 pasien dengan kondisi penyakit kronis yang mengalami keluhan nyeri lambung pada daerah fundus akibat penggunan OAINS. Serangan akibat Helicobacter pylori ditandai dengan keluhan rasa sakit pada daerah antrum sedangkan akibat penggunaan OAINS keluhan rasa sakit dirasakan pada daerah fundus ${ }^{9}$.

Kondisi penyakit tukak peptik akut berpotensi membahayakan dan lokasi nyeri lambung pada daerah fundus merupakan tukak yang disebabkan oleh stress ${ }^{9}$. Terdapat 18 pasien yang mengalami keluhan nyeri perut akut pada daerah fundus yang merupakan tukak akibat stres. Stres bisa diakibatkan oleh trauma, syok, menderita luka bakar dan faktor lingkungan yang kurang mendukung.Dalam hal ini pasien dianjurkan untuk menurunkan tingkat stres dengan memperbanyak istirahat dan menenangkan pikiran. Karena stres merupakan salah satu faktor yang dapat meningkatan sekresi asam lambung yang mengganggu pencernaan.

\begin{tabular}{|c|c|c|}
\hline Faktor penyebab tukak peptik & Jumlah & Persentase \\
\hline Helicobacter pylori & 19 & $38 \%$ \\
\hline OAINS & 5 & $10 \%$ \\
\hline Stres & 18 & $36 \%$ \\
\hline H.pylori - OAINS & 8 & $16 \%$ \\
\hline Total & 50 & $100 \%$ \\
\hline
\end{tabular}

\section{Hubungan hasil pemeriksaan fisik dengan pilihan terapi tukak peptik}

Sebanyak 27 pasien (54\%) dari total 50 pasien yang tidak berhubungan antara hasil pemeriksaan fisik dengan pilihan terapi tukak peptik, sisanya 23 pasien (46\%) yang berhubungan antara hasil pemeriksaan fisik dengan pilihan terapi tukak peptik. Pemeriksaan fisik untuk penyakit tukak peptik dapat dilakukan dengan menggali informasi dengan mengajukan pertanyaan seperti di mana lokasi nyeri pada perut dan kondisi penyakit.dan tukak akibat stres adalah akut. Data selengkapnya dapat dilihat pada tabel berikut.

Tabel 5. Hubungan hasil pemeriksaan fisik dengan pilihan terapi

\begin{tabular}{ccc}
\hline $\begin{array}{c}\text { Hubungan hasil pemeriksaan } \\
\text { fisik dengan pilihan terapi }\end{array}$ & $\mathrm{Jml}$ & Persentase \\
\hline Tidak berhubungan & 27 & $54 \%$ \\
Ada hubungan & 23 & $46 \%$ \\
\hline Total & 50 & $100 \%$ \\
\hline
\end{tabular}

Pada penelitian ini dari 50 pasien tukak peptik hanya 6 orang diantaranya yang menjalani pemeriksaan endoskopi. Hal ini terjadi karena biaya yang dikeluarkan untuk melakukan pemeriksaan endoskopi cukup 
mahal, Selain itu rasa tidak nyaman atau sakit membuat pasien menolak untuk melakukan pemeriksaan endoskopi. Pemberian terapi terhadap pasien yang melakukan pemeriksaan endoskopi atau tidak melakukan pemeriksaan endoskopi adalah sama. Pasien dengan keluhan atau tanpa keluhan dispepsia, American Gastroenterological Association merekomendasikan strategi " tes dan terapi". Pada terapi ini pasien harus melakukan tes Helicobacter pyloriseperti, tes serologi atau urea breath test(UBT). Jika hasilnya positif pasien harus mendapatkan terapi eradikasi selama 10-14 hari (Talley, 2003). Regimen terapi yang digunakan adalah International Guidelines for Helicobacter pylori ${ }^{18,19,20}$.

Tes non endoskopi dengan caraUrea Breath Test yang memiliki sensitifitas $90-95 \%$ dan spesifitas 98-99\% (Dzierzanowska et al, 2006). Tes serologi dapat dijadikan alternatif untuk diagnosa awal infeksi Helicobacter pylori karena harganya lebih terjangkau. Disinilah fungsi apoteker dalam memberikan pelayanan terapi yang paling efektif dan murah kepada pasien yang seharusnya dijalankan dengan baik.Hal ini sesuai dengan standar pelayanan farmasi di rumah sakit No. 1197/2004. Karena orientasi pelayanan kefarmasian saat ini telah bergeser lebih ke arah pelayanan kefarmasian klinik (Pharmaceutical Care), yaitu bentuk pelayanan dan tanggung jawab langsung profesi apoteker dalam pekerjaan kefarmasian untuk meningkatkan kualitas hidup pasien.Hal inilah yang menjadi poin penting peran apoteker di rumah sakit ${ }^{21}$. Kemudian apoteker harus mampu dalam melakukan penilaian terhadap hasil pemeriksaan fisik. Penilaian pemeriksaan fisik didefinisikan sebagai pengumpulan data tentang kondisi penyakit yang diderita pasien.Apoteker dapat menggunakan keterampilan penilaian untuk mengumpulkan data klinis yang penting sehingga dapat membantu dalam rujukan pengobatan. Apoteker harus memiliki pengetahuan tentang semua teknik penilaian untuk masing-masing daerah tubuh. Apoteker harus memiliki pengetahuan tentang kondisi penyakit, keluhan-keluhan yang biasa timbul akibat penyakit. Pemeriksaan fisik untuk penyakit tukak peptik dapat dilakukan dengan menggali informasi dengan mengajukan pertanyaan seperti di mana lokasi nyeri pada perut dan kondisi penyakit. Untuk lokasi nyeri yang disebabkan oleh Helicobacter pylori adalah pada daerah antrum atau perut bawah bagian kiri, dan untuk tukak akibat penggunaa OAINS dan stres adalah pada daerah fundus atau ulu hati. Mengetahuai kondisi menderita penyakit tukak peptic, untuk tukak akibat Helicobacter pylori dan penggunaan OAINS kondisinya sudah kronis dan tukak akibat stres kondisinya akut dan sering didaerah fundus.

Jika semua apoteker berperan untuk meningkatkan pelayanannya dan mempunyai niat baik untuk memperbaiki situasi 
kefarmasian, serta bisa bekerjasama dengan sejawat kesehatan lainnya maka harkat dan martabat apoteker bisa diraih kembali.

\section{KESIMPULAN}

Hasil penelitian yang telah dilakukan, dapat disimpulkan sebagai berikut:

Dari 50 pasien terdapat 23 pasien (46\%) yang berhubungan antara hasil pemeriksaan fisik dengan pilihan terapi tukak peptik, sisanya 27 pasien (54\%) yang tidak berhubungan antara hasil pemeriksaan fisik dengan pilihan terapi tukak peptik.

Hasil pemeriksaan fisik belum menjadi rujukan dalam pemberian terapi.

\section{SARAN}

Penelitian ini merupakan penelitian tahap awal, untuk peneliti selanjutnya agar mendapatkan hasil yang lebih akurat dilakukan tes pemeriksaan Helicobacter pylori dengan jumlah sampel yang lebih besar. Disarankan kepada apoteker mempunyai pengetahuan tentang penyakit sehingga bisa merekomendasikan terapi obat dengan tepat

\section{DAFTAR PUSTAKA}

1. Crawford J.M, 2005, The Gastrointestinal Tract, In V. Kumar, A.K. Abbas, N.Fausto ed.: Pathologic Basic of Disease. 7th ed. Philadelphia: Elsevier Saunders. p. 816-817.

2. Aziz, A.R., Achmad, F., 2006, Infeksi Helicobacter pylori dan Penyakit Gastroduodenal, ed: Buku Ajar Ilmu Penyakit Dalam ed IV Jilid I, FKUI. p.329

3. Dipiro, J.T., Cecily, Barbara, G.S., Terry, L.S., 2009, Pharmacotherapy Handbook,
Seventh Edition, McGraw-Hill Companies, Inc.

4. Kuipers, E.J., Thijs, J.C., Festen, H.P., The Prevalence of Helicobacter pylori in Peptik Ulcer Disease, Aliment Pharmacol Ther 1995; 9(Suppl 2):59-69.

5. Kimble, M.A., Young, L.E., Kradjan, W.A., Guglielmo, B.J., Alldredge, B.K., Corelli, R.L., 2005, Applied Therapentics : The Clinical Use of Drugs, $8^{\text {th }}$ Ed., Lippincot Williams \& Wilkins, USA.

6. Bhowmik, Chiranjib, K.K., Tripathi, Pankaj, K.P., Sampath, K., 2010,Recent Trends of Treatment and Medication Peptik Ulcerative Disorder, Pharm Tech, Vol2(1): 970-980.

7. Hardman, J.G., Limbird, L.E., Molinof, P.B., Ruddon, R.W., 2006, The Pharmacological Basic of Therapeutics, $9^{\text {th }}$ Ed., The McGraw-Hill Companies Inc., USA.

8. Longe, R.L., 1995, Teaching Physical Assessment to Doctor of Pharmacy Students, American Journal of Pharmaceutical Education, Vol. 59: 151-154.

9. Berardi, R.R., Welage, L.S, 2005, Peptic Ulcer Disease, In Dipiro J.T., Talbert R.L.,Yee G.C., Matzke G.R., Wells B.G., Posey L.M, ed: Pharmacotherapy aPathophysiologic Approach, 6th ed. USA: McGraw-Hill Companies. p. 630

10. Zeitoun, A., Mayam, Z., Hani, D., 2011, Stres Ulcer Prophylaxis Guidelines. Word Journal GastrointestinalPharmacology and Therapeutics, 2(4): 27-35.

11. Valle, D.J., Chey, W.D., Scheiman, J.M., Acid peptik disorders. In: Yamada, T., Aplers, D. H., Kaplowitz, N., Textbook of Gastroenterology, 4th ed, 2003, Philadelphia, Lippincott Williams \& Wilkins:1321-1376.

12. Xiang, Z., Min, J.S., Huai, D.H., 2004, Chronik Gastritis Rat Model and Role of Inducing Factor, Word Journal of Gastroenterology, China.

13. Awofisayo, O.S., Awofisayo, O.A., Iferi, I.I., \& Akpan, O.E. 2008. The Pattern of Sale and Use of Non-Steroidal AntiInflammatory Drugs in Rural and Urban Centres in Nigeria.Tropical Journal of Pharmaceutical Research, 7 (3) : 1013-1018

14. Goodman \& Gilman's. 2008. Manual of Pharmacology and Therapeutics. United States : The McGraw-Hill Companies

15. Risser, A., Donovan, D., Heintzman, J., \& Page, T. 2009. NSAID Prescribing Precaution.American Family Physician, 80 (12) : 1371-1378 
16. Roach, Sally. 2006. Introductory Clinical Pharmacology $\left(8^{\text {th }}\right.$ ed). United States : Lippincoot Williamsand Wilkins

17. Talley, Nicholas, J., 2003, Dyspepsia, Gastroenterology; 125: 1219-1226.

18. McLoughlin, Ramona, M., Colm, A., O'Morain, Humphrey, J., O'Connor, 2005, Eradication of Helicobacterpylori: recent advances intreatment, Fundamental\& Clinical Pharmacology19: 421-427.

19. Chey, W.D., Wong, B.C., 2007, American college of Gastroenterology Guideline on the Management of Helicobacter pylori, Am J Gastroenterol; 102: 1808-1825.
20. Malfertheiner, P., Megraude, F., Banzzoli, F., 2007, The European Helicobacter Study Group. Curret concepts in the management of Helicobacter pylori infection: the Maastricht III Consensus Report. Gut; 56: 772-781.

21. Susilowati, E. 26 Mei 2011 .Mengenal Lebih Dekat "Farmasi Klinik" (2), Diakses pada $\quad 1 \quad$ Mei 2012 dari http://www.putraindonesiamalang.or.id/men genal-lebih-dekat- $\%$ E2\%80\%9Cfarmasiklinik\%E2\%80\%9D-2.htm. 